\title{
Sobre a concepção relacional de linguagem em Nietzsche*
}

\author{
Eder Corbanezi** $^{* *}$
}

\begin{abstract}
Resumo: Depois de formular expressamente uma concepção relacional de linguagem em Sobre verdade e mentira no sentido extramoral, só raramente Nietzsche voltará a associar de maneira explícita os conceitos de linguagem e relação, como ocorre notadamente num fragmento póstumo de 1888. Gostaríamos, porém, de propor a hipótese de que em momento algum o filósofo abandona sua concepção relacional de linguagem; por outro lado, parece-nos que no decurso da obra ela passa por modificações, que devem ser identificadas.
\end{abstract}

Palavras-chave: linguagem - relação - transposição - perspectiva avaliadora

"A exigência de um modo de expressão adequado é absurda", escreve Nietzsche em seu último ano de produção intelectual, e acrescenta: "está na essência de uma linguagem, de um meio de expressão, expressar uma mera relação" (Nachlass/FP 1888, 14[122], KSA 13.303$)^{1}$. Mas a formulação de uma concepção relacional de linguagem não é propriamente tardia. Ao contrário, aparece literalmente no ensaio de 1873 intitulado Sobre verdade e mentira no

\footnotetext{
* Agradeço aos integrantes do Grupo de Estudos Nietzsche da USP que discutiram o texto ainda em fase de elaboração.

** Mestre em Filosofia pela Universidade de São Paulo (USP), São Paulo, Brasil. Endereço eletrônico: edercorbanezi@hotmail.com.

1 É relevante notar desde já que em diversas ocasiões Nietzsche se beneficia do caráter plurívoco do termo alemão Sprache, que, segundo o contexto, pode-se traduzir tanto por língua quanto por linguagem. Para as citações dos textos de Nietzsche, utilizamos, sempre que possível, as traduções de Rubens Rodrigues Torres Filho (RRTF) e de Paulo César de Souza (PCS). Nos demais casos, as traduções são de nossa responsabilidade.
} 
sentido extramoral, onde se lê que "o formador da linguagem [...] designa apenas as relações das coisas aos homens" (WL/VM 1, KSA 1.879, trad. RRTF).

Se nas duas passagens Nietzsche confere um caráter relacional à linguagem, contrapondo-se à possibilidade de uma expressão adequada da realidade, o considerável espaço temporal que separa ambos os textos suscita, de maneira legítima, a suspeita de que o sentido de sua concepção relacional não permanece o mesmo. A tarefa que se coloca então consiste em identificar as possíveis transformações ocorridas nesse ínterim. Logo de início, porém, tal proposta se depara com uma dificuldade: a escassez, para dizer o mínimo, de escritos redigidos naquele intervalo que vinculem expressamente os conceitos de linguagem e relação. Mas esse obstáculo não representa por si só um impedimento definitivo, já que a raridade ou mesmo a ausência de um termo não implicam necessariamente a inexistência ou a insignificância da ideia que lhe corresponde na obra em questão, embora possam de fato dificultar sua identificação e análise.

No presente estudo, apresentamos a hipótese de que Nietzsche não abandona sua concepção relacional de linguagem, que passa, todavia, por transformações no decorrer de sua obra. Nesse sentido, propomo-nos a identificar algumas dessas modificações, as quais fazem parte de um conjunto de reflexões extremamente multifacetadas sobre a linguagem.

Procuraremos evidenciar, num primeiro momento, que em $\mathrm{So}$ bre verdade e mentira no sentido extramoral Nietzsche apresenta sua concepção relacional de linguagem de maneira explícita e bem delimitada. Para mostrar por que "o formador da linguagem [...] designa apenas as relações das coisas aos homens" (WL/VM 1, KSA 1.879, trad. RRTF), o autor do ensaio examina a "gênese da linguagem" (WL/VM 1, KSA 1.878, trad. RRTF), procedimento que ali coincide com uma investigação direcionada em especial ao processo de constituição das palavras e dos conceitos. Com isso, indica que as palavras e os conceitos são relativos na medida em

168 I Cad. Nietzsche, São Paulo, n. 34 - vol. I, p. 167-187, 2014. 
que dependem de uma série de transposições - também denominadas relações - entre esferas diferentes. Ao procurar estabelecer seu caráter com maior precisão, o filósofo defende que não se trata de relações necessárias, tampouco de causalidade e menos ainda de correspondência, mas de relações estéticas. Assim, faz ver que as designações não expressam adequadamente a realidade nem verdades absolutas, mas tão somente relações antropomórficas.

Analisando passagens de Para a genealogia da moral, tentaremos mostrar, num segundo momento, que é à luz do conceito de vontade de potência que Nietzsche se voltará novamente à investigação sobre a origem da linguagem e sobre a constituição das palavras e dos conceitos, isto é, das designações, assim como sobre o predomínio de determinadas funções gramaticais. Se outrora sustentara que as palavras e os conceitos, constituídos por um processo metafórico, não expressam verdades absolutas, nesse novo contexto é outro o interesse do genealogista: concebendo toda linguagem como sintoma a ser interpretado, examinará os modos de constituição das designações e as próprias significações das palavras e dos conceitos, bem como a crença em certos tópicos gramaticais, para defender que eles traduzem diferentes interpretações de mundo e se reportam a diferentes tipos de moral e de homem. Com efeito, uma determinada linguagem é sempre relativa a uma perspectiva avaliadora.

I.

Em A filosofia na época trágica dos gregos, Nietzsche afirma que "as palavras são apenas símbolos para as relações das coisas entre si e para conosco e não tocam, em parte alguma, a verdade absoluta" (PHG/FT 11, KSA 1.846); pouco adiante, insiste que "por meio de palavras e conceitos nunca chegaremos atrás da parede das relações, como a um fabular fundamento original das coisas" (PHG/FT 11, KSA 1.846). 
Mas é em Sobre verdade e mentira no sentido extramoral que o filósofo oferece mais detalhes de sua concepção relacional de linguagem ${ }^{2}$. De início, apresenta algumas perguntas que apontam a direção de suas reflexões: "O que se passa com aquelas convenções da linguagem? São talvez frutos do conhecimento, do senso de verdade: as designações e as coisas se recobrem? É a linguagem a expressão adequada de todas as realidades?" (WL/VM 1, KSA 1.878, trad. RRTF). Além de sugerir o aspecto convencional da linguagem sustentado pelo próprio autor do texto, essas questões indicam a concepção linguística em relação à qual procura posicionar-se: ali, tem-se em vista uma certa tradição que atribuíra às palavras e aos conceitos o estatuto de expressão adequada da realidade e de verdades absolutas. A resposta àquelas interrogações é, contudo, taxativa: "As diferentes línguas, colocadas lado a lado, mostram que nas palavras nunca importa a verdade, nunca uma expressão adequada" (WL/VM 1, KSA 1.879, trad. RRTF). Em vez disso, propõe Nietzsche, "o formador da linguagem [...] designa apenas as relações das coisas aos homens e toma em auxílio para exprimi-las as mais audaciosas metáforas" (WL/VM 1, KSA 1.879, trad. RRTF).

Para compreender por que a linguagem designa somente "relações", é preciso antes de tudo estabelecer o que é uma palavra: "A figuração de um estímulo nervoso em sons", escreve o filósofo, para adiante explicitar seu processo de constituição: "Um estímulo nervoso, primeiramente transposto em uma imagem! Primeira metáfora. A imagem, por sua vez, modelada em um som! Segunda metáfora. E a cada vez completa mudança de esfera, passagem para uma esfera inteiramente outra e nova" (WL/VM 1, KSA 1.878879, trad. RRTF) ${ }^{3}$.

2 "Em seu texto sobre Verdade e mentira no sentido extramoral, Nietzsche começa por pensar a linguagem enquanto relação", escreve Scarlett Marton (cf. Le problème du langage chez Nietzsche. La critique en tant que création. In: Revue de Métaphysique et de Morale, Paris, n. 2, 2012, p. 227).

3 Diversos comentadores investigaram a influência da primeira parte do livro Die Sprache als Kunst, de Gustav Gerber, sobre Nietzsche a respeito desse e de muitos outros pontos. Entre 
Aqui, metáfora não possui o sentido estrito de uma figura de linguagem particular. Significa, em sentido amplo, as transposições entre esferas heterogêneas que têm lugar no processo de constituição das palavras ${ }^{4}$. Deve-se então determinar de maneira mais precisa o caráter de tais transposições, às quais Nietzsche também se refere, justamente, como relações.

Procurando caracterizá-las de um modo negativo, o filósofo defende que "a relação entre um estímulo nervoso e a imagem produzida não é em si necessária" (WL/VM 1, KSA 1.884); recusa ainda que "a relação entre o estímulo nervoso original e a imagem produzida seja uma estrita relação de causalidade" (WL/VM 1, KSA 1.884). E isso vale até mesmo para os casos em que a mesma imagem se reproduz inúmeras vezes, casos que erroneamente poderiam levar a crer que entre estímulo nervoso e imagem exista uma relação necessária e causal. Para sustentar suas posições, o autor do ensaio sublinha a natureza subjetiva dos estímulos nervosos e assevera que "concluir do estímulo nervoso uma causa fora de nós já é resultado de uma aplicação falsa e ilegítima do princípio da razão" (WL/VM 1, KSA 1.878, trad. RRTF).

Com isso, Nietzsche não propõe que as palavras não possam, de maneira alguma, referir-se a algo exterior. Trata-se antes de

outros, cf. MEIJERS, A. Gustav Gerber und Friedrich Nietzsche. In: Nietzsche-Studien 17. Berlim e Nova York: Walter de Gruyter, 1988; CRAWFORD, C. The Beginnings of Nietzsche's Theory of Language. Berlim e Nova York: Walter de Gruyter, 1988, em especial p. 199-219; ZAVATTA, B. Die in der Sprache versteckte Mythologie und ihre Folgen fürs Denken. Einige Quellen von Nietzsche: Max Müller, Gustav Gerber und Ludwig Noiré. In: Nietzsche-Studien 38. Berlim e Nova York: Walter de Gruyter, 2009; GUERVÓS, L. E. de S. Introducción: El poder de la palabra: Nietzsche y la retórica. In: NIETZSCHE, F. Escritos sobre retórica. Edição, tradução e introdução de Luis Enrique de Santiago Guervós. Madrid: Editorial Trotta, 2000; MEIJERS, A. e STINGELIN, M. Konkordanz zu den Wörtlichen Abschriften und Übernahmen von Beispielen und Zitaten aus Gustav Gerber: Die Sprache als Kunst (Bromberg 1871) in Nietzsches Rhetorik-Vorlesung und in 'Ueber Wahrheit und Lüge im aussermoralischen Sinne'. In: Nietzsche-Studien 17. Berlim e Nova York: Walter de Gruyter, 1988.

4 Cf. DENAT, C. "Parler par images": le statut de la rhétorique et des métaphores dans le "nouveau langage" de Nietzsche. In: DENAT, C.; WOTLING, P. (org.). Nietzsche. Un art nouveau du discours. Reims: Éditions et presses universitaires de Reims, 2013, em particular p. 68 et seq. 
defender que, se houver, essa relação jamais será de correspondência, dado o caráter heterogêneo das esferas envolvidas nas transposições - nas metáforas, em sentido amplo - por meio das quais se constituem as palavras: "Acreditamos saber algo das coisas mesmas, se falamos de árvores, cores, neve e flores, e no entanto não possuímos nada mais do que metáforas das coisas, que de nenhum modo correspondem às entidades de origem" (WL/VM 1, KSA 1.879, trad. RRTF). Por conta da heterogeneidade das esferas, as transposições não resultam em reproduções exatas, como evidencia o seguinte excerto das notas para um curso sobre retórica antiga ${ }^{5}$ :

O homem formador da linguagem não considera coisas ou processos, mas estímulos: ele não reproduz sensações, mas apenas figurações de sensações. A sensação provocada por um estímulo nervoso não capta a coisa mesma: essa sensação é representada externamente por uma imagem: mas em geral é preciso perguntar: como um ato da alma é representável por uma imagem sonora? Se uma reprodução perfeita e exata tivesse de ocorrer, antes de tudo o material em que se teria de reproduzir não deveria ser o mesmo que aquele em que trabalha a alma? Como, porém, se trata de um [material] heterogêneo - o som -, como pode então produzir-se aí algo mais exato do que uma imagem? Não as coisas entram na consciência, mas o modo como nos colocamos diante delas [...]. (KGW II/4, p. 426).

Se a impossibilidade de uma relação de correspondência entre as palavras e as coisas deve-se basicamente à heterogeneidade das esferas nas quais ocorrem as transposições que formam as palavras,

5 Segundo as anotações para o curso Darstellung der antiken Rhetorik, a retórica não se restringe a uma arte consciente, mas operou de maneira inconsciente no desenvolvimento da linguagem, que é, portanto, totalmente retórica. Assim, todas as palavras são, desde o princípio, tropos, isto é, significações impróprias, de modo que não captam a essência das coisas. Cf. KGW II/4, em particular p. 425-428, e também Nachlass/FP 1872-1873, 19[215], KSA 7.486, onde o filósofo afirma que as figuras retóricas constituem a essência da linguagem.

172 I Cad. Nietzsche, São Paulo, n. 34 - vol. I, p. 167-187, 2014. 
Nietzsche não deixa de chamar a atenção também para as "delimitações arbitrárias" que se operam nas designações (WL/VM 1, KSA 1.879, trad. RRTF). Com isso, além da arbitrariedade, acentua seu aspecto simplificador: "Falamos de uma Schlange (cobra): a designação não se refere a nada mais do que o enrodilhar-se, e, portanto, poderia também caber ao verme. Que delimitações arbitrárias, que preferências unilaterais, ora por esta, ora por aquela propriedade de uma coisa!" (WL/VM 1, KSA 1.878-879, trad. RRTF).

De fato, nas anotações para o mencionado curso sobre retórica, ao analisar com maior minúcia alguns tropos, Nietzsche já observara que a sinédoque é "muito poderosa na linguagem", que "nunca expressa algo de maneira completa, mas em toda parte destaca apenas a característica mais sobressalente" (KGW II/4, p. 445). Em todo caso, deve-se precisar a esse respeito que, como toda palavra resulta de um processo metafórico - isto é, de transposições entre esferas heterogêneas -, então aquelas "delimitações arbitrárias" não constituem simplificações meramente, por assim dizer, quantitativas: as palavras traduzem aquilo que significam de modo não só incompleto como também inexato.

Nietzsche examina ainda a maneira pela qual as palavras se tornam conceitos. Isso ocorre quando, em vez de servir como recordação para a vivência individual de que surge, uma palavra passa a convir a inúmeros casos semelhantes, ou seja, desiguais: é da "igualação do não-igual" e da " desconsideração do individual e efetivo" que nasce o conceito (WL/VM 1, KSA 1.880, trad. RRTF). Recorrendo a exemplos, o filósofo evidencia o processo pelo qual um conceito, mero signo, é substancializado e tomado como uma coisa capaz de produzir efeitos. Ao terem seus aspectos desiguais desconsiderados, ações as mais diversas são tomadas por iguais e designadas como honestas: "por fim, formulamos a partir delas uma qualitas occulta com o nome: "a honestidade" (WL/VM 1, KSA 1.880, trad. RRTF). E assim se diz que um homem é honesto "por causa de sua honestidade" (WL/VM 1, KSA 1.880, trad. RRTF). 
"Aqui temos uma transposição", resume o filósofo numa nota póstuma, "uma abstração reúne inúmeras ações e vale como causa" (Nachlass/FP 1872-1873, 19[215], KSA 7.486) 7 .

Incorre-se desse modo num uso ingênuo da linguagem. Em primeiro lugar, abstrai-se uma qualidade, a honestidade, de inúmeras ações desiguais que, sob um certo aspecto, são concebidas como iguais: neste caso, como honestas; em seguida, toma-se tal abstração, simples nome instituído depois das ações, como uma coisa, e, mais precisamente, uma coisa que seria a causa daquelas ações. Nas anotações para o curso sobre retórica, depois de escrever que também a metonímia é "muito poderosa na linguagem", Nietzsche explicita o processo metonímico, caracterizado pela confusão de causa e efeito, na constituição dos conceitos: "Aqueles conceitos, que devem sua origem meramente a nossas sensações, são pressupostos como essência intrínseca das coisas: atribuímos como causa dos fenômenos o que é, contudo, apenas consequência. Os [substantivos] abstratos suscitam a ilusão de que eles seriam aquela essência que causa as propriedades, enquanto eles, apenas em consequência daquelas propriedades, recebem de nós uma existência figurada" (KGW II/4, p. 446).

A rigor, porém, as chamadas propriedades das coisas nada mais são do que relações: "As propriedades contêm apenas relações" (Nachlass/FP 1872-1873, 19[242], KSA 7.495). E, mais especificamente, relações humanas: “Que uma unidade, uma árvore, p. ex., apareça para nós como pluralidade de propriedades, de relações,

6 No fragmento mencionado, Nietzsche atribui outro sentido aos termos "transposição" e, por conseguinte, "metáfora". Eles não se referem apenas ao processo de constituição de palavras e conceitos, mas também ao procedimento em que se postula a existência absoluta de algo que nada mais é, em última instância, do que uma concepção subjetiva. O filósofo explora, com nuances, esse último sentido em contextos diversos; por exemplo, ao afirmar: "Mas transportar para a natureza o impulso de ser verdadeiro produz a crença de que também a natureza deve ser verdadeira em relação a nós. [O] impulso do conhecimento repousa nessa transposição" (Nachlass/FP 1872-1873, 19[230], KSA 7.492).

7 "As abstrações são metonímias, isto é, confusão de causa e efeito. Mas todo conceito é uma metonímia e o conhecer ocorre por conceitos (Nachlass/FP 1872-1873, 19[204], KSA 7.481)."

174 I Cad. Nietzsche, São Paulo, n. 34 - vol. I, p. 167-187, 2014. 
é antropomórfico em um duplo modo: primeiro, essa unidade delimitada 'árvore' não existe, tem-se de recortar arbitrariamente uma coisa assim (segundo o olho, segundo a forma), nenhuma relação é a relação verdadeira, absoluta, mas de novo antropomorficamente colorida" (Nachlass/FP 1872-1873, 19[236], KSA 7.494).

$\mathrm{O}$ modo como se constituem as palavras e os conceitos indica que eles não são expressão adequada da realidade nem verdades absolutas. Antes, aquilo que se denominara verdade se revela afinal "um batalhão móvel de metáforas, metonímias, antropomorfismos, enfim, uma soma de relações humanas, que foram enfatizadas poética e retoricamente, transpostas, enfeitadas" (WL/VM 1, KSA 1.880 , trad. RRTF).

Depois de investigar o processo de formação de palavras e conceitos, Nietzsche descarta a possibilidade de uma "expressão adequada de um objeto no sujeito" e afirma que entre esferas tão distintas não existe mais do que uma relação estética, na qual sempre ocorre uma tradução para uma linguagem completamente heterogênea: "Pois entre duas esferas absolutamente diferentes como entre sujeito e objeto não há nenhuma causalidade, nenhuma exatidão, nenhuma expressão, mas no máximo uma relação estética, quero dizer, uma transposição alusiva, uma tradução balbuciante para uma linguagem totalmente heterogênea" (WL/VM 1, KSA 1.884).

Se as designações não expressam adequadamente a realidade nem verdades absolutas, resta ainda a determinar qual é e como se estabelece de fato o vínculo entre a linguagem e aquilo que se tomara como verdade, bem como especificar o papel que um certo

8 Se defende que, estabelecendo somente relações antropomórficas com as "coisas", o homem é incapaz de alcançar algo absoluto e independente, ao mesmo tempo Nietzsche nuança essa posição ao apontar para a insuficiência da própria ideia de antropomorfismo. Considerando que "conhecimento" significa "identificar o não-igual, o semelhante", o filósofo pondera sobre a aplicação de tal procedimento ao caso específico do conceito de homem: "Somente por esse caminho produzimos um conceito, e depois agimos como se o conceito 'homem' fosse algo fático, enquanto ele é, porém, formado por nós, apenas por meio do abandono de todos os traços individuais" (Nachlass/FP 1872-1873, 19[236], KSA 7.494). 
uso das designações cumpre nesse contexto. É o que faz Nietzsche ao dizer que o primeiro passo para o impulso à verdade se dá com o tratado de paz que procura pôr fim à máxima "bellum omnium contra omnes", para que o homem possa viver socialmente: "Agora, com efeito, é fixado aquilo que doravante deve ser 'verdade', isto é, é descoberta uma designação uniformemente válida e obrigatória das coisas, e a legislação da linguagem dá também as primeiras leis da verdade: pois surge aqui pela primeira vez o contraste entre verdade e mentira" (WL/VM 1, KSA 1.877, trad. RRTF) ${ }^{9}$.

Vinculada à linguagem - mais exatamente, à determinação de uma designação válida e obrigatória -, a verdade tem um caráter convencional e imperativo. Para existir enquanto tal, a sociedade exige obediência ao imperativo de "dizer a verdade, isto é, de usar as metáforas usuais", o que, "expresso moralmente", significa uma "obrigação de mentir segundo uma convenção sólida, mentir em rebanho"(WL/VM 1, KSA 1.881, trad. RRTF). Com efeito, os homens evitam não o engano propriamente dito, mas as consequências nocivas da mentira, que consiste num determinado uso, desviante, das designações, a saber, no emprego das "designações válidas, as palavras, para fazer aparecer o não-efetivo como efetivo" (WL/VM 1, KSA 1.877, trad. RRTF). Do mesmo modo, os homens desejam as consequências da "verdade" - ou seja, do uso convencional das designações - que são agradáveis e conservadoras da vida, mas se mostrariam indiferentes diante de um conhecimento sem consequências e até hostis em face de verdades destrutivas. Assim como evitam uma espécie restrita de ilusão, acolhem uma espécie restrita de verdade.

É apenas ao ignorar os processos de constituição das palavras e dos conceitos que o homem vê na linguagem a expressão adequada da realidade, quando ela, segundo Nietzsche, "designa apenas as relações das coisas aos homens" (WL/VM 1, KSA 1.879, trad. RRTF).

9 Cf. Nachlass/FP 1872-1873, 19[229] e 19[230], KSA 7.491-492. 
É somente ao se esquecer daquela obrigação de ser "verídico", isto é, de mentir segundo uma convenção e empregar as designações metafóricas usuais, que o homem, mentindo inconscientemente, acredita estar em posse de verdades absolutas, que nada mais são do que "uma soma de relações humanas" (WL/VM 1, KSA 1.880, trad. RRTF).

II.

Ao afirmar, no já mencionado fragmento póstumo de 1888, que "está na essência de uma linguagem, de um meio de expressão, expressar uma mera relação" (Nachlass/FP 1888, 14[122], KSA 13.303), Nietzsche parece conservar até seus últimos escritos uma concepção relacional de linguagem, que passa a repousar, porém, em sua interpretação do mundo como vontade de potência.

A fim de evidenciarmos esse ponto, examinaremos em particular algumas passagens de Para a genealogia da moral. Em parte delas, Nietzsche dirige novamente sua atenção, de maneira metodológica, para o mesmo tópico da linguagem de que já tratara em outras ocasiões, a designação: interpretando, desta vez a partir do conceito de vontade de potência, diferentes maneiras de designar, ele identifica diferentes maneiras de instaurar valores, que apontam para uma moral de senhores ou para uma moral de escravos $^{10}$. Nas demais passagens, o filósofo se ocupa do exame de outro aspecto específico da linguagem, a distinção gramatical entre sujeito e verbo. Sua análise se baseia na ideia de que certas funções gramaticais induzem determinadas interpretações de mundo e inviabilizam outras, assim como traduzem certos tipos de moral. A partir daí, indica que, por um lado, a distinção entre sujeito e verbo advoga em favor de uma concepção substancialista de realidade e

10 Cf. GM/GM I, 2, 4 e 5, KSA 5.258-264. 
de uma moral de fracos que pressupõe a existência de um substrato livre para escolher agir ou não; em contrapartida, aquela separação gramatical vai de encontro à interpretação do mundo como vontade de potência e à moral correspondente ${ }^{11}$. Uma linguagem sempre é, pois, relativa a uma perspectiva avaliadora.

Em Para a genealogia da moral, Nietzsche não só retoma o exame das designações como também lhe atribui um papel metodológico no interior de seu procedimento investigativo: "A indicação do caminho certo me foi dada pela seguinte questão: que significam exatamente, do ponto de vista etimológico, as designações para ‘bom' cunhadas pelas diversas línguas?" (GM/GM I, 4, KSA 5.261, trad. PCS $)^{12}$. Com efeito, a investigação sobre a proveniência dos valores morais se vincula estreitamente ao exame da origem e das transformações das designações, conforme testemunha de maneira paradigmática a primeira dissertação do livro em questão.

Conferindo centralidade à análise das designações, o filósofo também indica, logo de início, de que perspectiva procederá em sua genealogia, a saber, de sua concepção de mundo como vontade de potência, como transparece na seguinte afirmação: "O direito dos senhores, de dar nomes, vai tão longe, que se poderia permitir-se captar a origem da linguagem mesma como exteriorização de potência dos dominantes: eles dizem 'isto é isto e isto', eles selam cada coisa e acontecimento com um som e, com isso, como que tomam posse dele" (GM/GM I, 2, KSA 5.260, trad. RRFT).

Nietzsche considera a própria origem da linguagem, tema que há muito lhe é caro $^{13}$, à luz do conceito de vontade de potência.

11 Cf. GM/GM I, 13, KSA 5.278-281.

12 Assim, Nietzsche se mostra em consonância com a pergunta que, segundo ele próprio, deve guiar os estudos histórico-morais: "Que indicações fornece a ciência da linguagem, em especial a pesquisa etimológica, para a história da evolução dos conceitos morais?" (GM/GM I, 17, KSA 5.289, trad. PCS). Sobre a centralidade das investigações etimológicas e linguísticas, cf. ainda o Nachlass/FP 1885, 38[14], KSA 11.613, em que anota: "A partir da etimologia e da história da linguagem, consideramos todo conceito como tendo vindo a ser, muitos como ainda vindo a ser".

13 As anotações referentes ao seu curso sobre gramática latina (Vorlesungen über lateinische

178 I Cad. Nietzsche, São Paulo, n. 34 - vol. I, p. 167-187, 2014. 
Assim, o denominar não é outra coisa senão "exteriorização de potência"14. Mas os senhores não são os únicos a darem nomes: outras perspectivas avaliadoras também o fazem. E, de fato, os modos de designar e valorar se revelam distintos conforme as diferentes perspectivas avaliadoras de que provêm. Nesse sentido, uma linguagem, segundo a concepção relacional que dela tem Nietzsche, é relativa porque sempre se reporta aos que a instituíram: ela não tem valor em si, mas como sintoma ${ }^{15}$. Por conseguinte, enquanto genealogista, o filósofo investiga os nomes - e os valores aos quais se vinculam - sempre em relação às perspectivas avaliadoras que os estabeleceram. Para isso, examina tanto os diferentes procedimentos de designação quanto as diversas significações atribuídas aos nomes - aos mesmos nomes, por vezes.

Ao contrário de uma dada genealogia que vê a proveniência do conceito "bom" nas "ações não-egoístas [...] denominadas boas por parte daqueles a quem foram demonstradas", Nietzsche defende que "foram antes 'os bons', eles próprios, isto é, os nobres, poderosos, mais altamente situados e de altos sentimentos, que sentiram

Grammatik) começam com observações reunidas sob o título "Da origem da linguagem" (KGW II/2, p.185-188). A partir de outra chave de leitura, Nietzsche revisita o assunto em Sobre verdade e mentira no sentido extramoral, como vimos na primeira parte deste estudo.

14 Evocando o mesmo texto de Nietzsche que acabamos de citar, Müller-Lauter afirma: "Falar é um modo de expressão do querer-potência" (cf. MÜLLER-LAUTER, W. Nietzsches Lehre vom Willen zur Macht. In: Nietzsche-Studien 3. Berlim e Nova York: Walter de Gruyter, 1974, p. 17). 15 A concepção de linguagem como sintoma não é uma novidade na trajetória de Nietzsche. Ao mesmo tempo em que sustenta que a linguagem não oferece verdades absolutas, o filósofo já a considera enquanto sintoma. Tal ideia se encontra, entre outras, nas afirmações de que "o declínio da formação se mostra no empobrecimento da língua" (Nachlass/FP 1874, 37[4], KSA 7.830), bem como de que "a pobreza de uma língua corresponde à pobreza das opiniões" (Nachlass/ FP 1874, 37[5], KSA 7.830). Nessa direção, Nietzsche diagnostica: "Reconheço muito bem no caráter embotado de nossa língua nosso caráter alemão, que se tornou embotado, nossa individualidade evanescente"; e conclui: "o empobrecimento e a palidez da língua são um sintoma da alma universal atrofiada na Alemanha" (Nachlass/FP 1874, 37[7], KSA 7.833-834). Por outro lado, se "a língua comum é a expressão sonora de uma alma comum", escreve Nietzsche em outro fragmento, então "um povo que tem seis casos e flexiona seus verbos em cem formas possui uma alma repleta, comum e transbordante; e o povo que criou para si uma língua assim derramou a plenitude de sua alma por toda a posteridade" (Nachlass/FP 1874, 37[6], KSA 7.831-832). Se as línguas não expressam adequadamente a realidade, daí não resulta que elas se equivalham.

Cad. Nietzsche, São Paulo, n. 34 - vol. I, p. 167-187, 2014. | 179 
e puseram a si mesmos e a seu próprio fazer como bons, ou seja, de primeira ordem, por oposição a tudo o que é inferior, de sentimentos inferiores, comum e plebeu". E prossegue: "Desse pathos da distância é que tomaram para si o direito de criar valores, de cunhar nomes dos valores [...]. O pathos da nobreza e da distância, como foi dito, o duradouro e dominante sentimento global e fundamental de uma espécie superior de senhores, posta em relação com uma espécie inferior, com um 'abaixo' - essa é a origem da oposição 'bom' e 'ruim"' (GM/GM I, 2, KSA 5.259, trad. RRFT modificada).

Por um lado, então, conforme a instituição de nomes e valores por parte dos senhores, "a palavra 'bom"” não se vincula necessariamente à ideia de não egoísmo, ao contrário do que supuseram os criticados genealogistas. Por outro lado, é somente quando - "para me servir de minha linguagem", destaca Nietzsche - "o instinto de rebanho [...] toma a palavra (e também as palavras)" que passa a dominar "o preconceito que toma 'moral', "não-egoísta', désintéressé" como conceitos de igual valor" (GM/GM I, 2, KSA 5.260, trad. RRFT). Assim, o sentido das palavras e as relações que se estabelecem entre elas dependem da perspectiva avaliadora a que remontam. Da mesma maneira, as diferentes genealogias da moral também provêm de diferentes perspectivas avaliadoras.

Examinando o modo como os senhores, os poderosos, se autodesignavam e designavam aqueles dos quais se queriam distinguir, Nietzsche constata "que, nas palavras e raízes que designam o 'bom', transparece ainda com frequência a nuance cardeal pela qual os nobres se sentiam homens de categoria superior" (GM/GM I, 5, KSA 5.262, trad. PCS). É assim que "o nobre, que primeiro e espontaneamente, de dentro de si, concebe a noção básica de 'bom', [...] a partir dela cria para si uma representação de "ruim"" (GM/GM I, 11, KSA 5.274, trad. PCS).

De outra forma procede a moral do ressentimento, que concebe “o inimigo mau', 'o mau' [...] como conceito básico, a partir do qual também elabora, como imagem equivalente, um 'bom' - ele mesmo!" (GM/GM I, 10, KSA 5.274, trad. PCS). Enquanto o "ruim" 
de origem nobre consiste tão somente numa "criação posterior, secundária, cor complementar", "o mau" dos fracos e impotentes é, ao contrário, "o original, o começo, o autêntico feito na concepção de uma moral escrava" (GM/GM I, 11, KSA 5.274, trad. PCS).

As designações "bom e ruim" e "mau e bom" se reportam a origens distintas; perspectivística, a relação entre aqueles que designam e os signos é sempre diversa. Por conseguinte, a mesma palavra empregada para designar um determinado valor pode abrigar uma pluralidade de sentidos, conforme a perspectiva avaliadora ${ }^{16}$. Na perspectiva avaliadora da moral nobre, o valor "bom" não possui o mesmo significado que na perspectiva avaliadora da moral escrava. Ao perguntar-se quem é "mau" no sentido da moral do ressentimento, Nietzsche responde: “Precisamente o 'bom' da outra moral, o nobre, o poderoso, o dominador, apenas pintado de outra cor, interpretado e visto de outro modo pelo olho de veneno do ressentimento" (GM/GM I, 11, KSA 5.274, trad. PCS $)^{17}$.

16 A esse respeito, cf. MARTON, S. Nietzsche: das forças cósmicas aos valores humanos. Belo Horizonte: Editora UFMG, $2^{\text {a }}$ ed., 2000, p. 94, de onde também retiramos a expressão "perspectiva avaliadora", central em nosso estudo.

17 No parágrafo 268 de Para além de bem e mal, Nietzsche reexamina um tema já tratado em Sobre verdade e mentira no sentido extramoral ao afirmar: "Palavras são sinais sonoros para conceitos; mas conceitos são sinais-imagens, mais ou menos determinados, para sensações recorrentes e associadas, para grupos de sensações" (JGB/BM 268, KSA 5.221, trad. PCS). Mas o filósofo precisa que, para haver entendimento mútuo, não basta que se fale a mesma língua e se utilizem as mesmas palavras: é necessário ainda que se partilhem vivências, experiências e condições semelhantes. Só assim se evitarão, no perigo ou na amizade, mal-entendidos, que ocorrem, por exemplo, se "um dos parceiros, usando as mesmas palavras, sente, pensa, pressente, anseia, receia de modo diferente do outro" (Ibid., p. 222). Com isso, Nietzsche indica que se podem estabelecer diferentes relações com as palavras, inclusive com as mesmas palavras, segundo as vivências singulares daqueles que as utilizam. É bem verdade que, por outro lado, "a necessidade aproximou apenas aqueles que podiam, com sinais semelhantes, indicar vivências semelhantes" (Ibid., p. 222). De todo modo, é a própria relação entre signos e vivências que deve ser objeto de exame, pois, segundo uma concepção sintomática de linguagem, traduz uma determinada hierarquia de valores: "Quais os grupos de sensações que dentro de uma alma despertam mais rapidamente, tomam a palavra, dão as ordens: isso decide a hierarquia inteira de seus valores, determina por fim a sua tábua de bens" (Ibid., 222). É nesse sentido que Nietzsche procura identificar se as designações provêm do pathos da distância dos senhores ou se é o instinto de rebanho que toma a palavra (GM/GM I, 2, KSA 5.259-260). Cumpre notar por fim que, se mais uma vez reconduz as palavras e os conceitos às 
Além das denominações, o genealogista se detém no exame de outro tópico da linguagem, a separação gramatical entre sujeito e verbo. Sua investigação repousa sobre a ideia de que o predomínio de determinadas "funções gramaticais" induz uma determinada "interpretação do mundo" ao passo que inviabiliza outras: é de acordo com essa forma de raciocinar que Nietzsche supõe, por exemplo, que os filósofos do domínio linguístico uralo-altaico, em que o conceito de sujeito se desenvolveu mal, lancem ao mundo um olhar diferente em comparação aos indo-germânicos e aos muçulmanos (JGB/BM 20, KSA 5.34-35, trad. PCS) ${ }^{18}$. Além de possibilitar certas interpretações de mundo e obstruir outras, o predomínio de certas funções gramaticais se reporta - acrescenta Nietzsche - a uma constituição fisiológica e a uma moral determinadas: "o encanto exercido por determinadas funções gramaticais é, em última instância, o encanto de condições raciais e juízos de valor fisiológicos" (JGB/BM 20, KSA 5.35, trad. PCS) ${ }^{19}$.

\footnotetext{
sensações, o filósofo parece agora raciocinar conforme a lógica da vontade de potência, como sugere a pergunta por "quais grupos de sensações dentro de uma alma [...] tomam a palavra, dão as ordens". A respeito da "linguagem" dos impulsos, cf. WOTLING, P. What Language Do Drives Speak?. In: CONSTÂNCIO, J.; BRANCO, M. J. M (Ed.). Nietzsche on Instinct and Language. Berlim e Boston: de Gruyter, 2011, p. 63-79. Ao examinar o problema da linguagem dos impulsos e do entendimento entre eles, Wotling conclui que existe "uma linguagem infraconsciente, isto é, uma linguagem que não se traduz em palavras (o que nos levaria a um nível consciente), mas [que] finalmente as torna possível" (Ibid., p. 77-78); nesse nível elementar, a "linguagem" se basearia em avaliações de disparidades de potência.

18 Para Albrecht, o parágrafo 20 de Para além de bem e mal é o texto em que o Nietzsche maduro apresenta sua formulação do "princípio de relatividade linguística" (cf. ALBRECHT, J. Friedrich Nietzsche und das "sprachliche Relativitätsprinzip". In: Nietzsche-Studien 8. Berlim e Nova York: Walter de Gruyter, 1979, p. 236). Segundo tal princípio, uma determinada interpretação de mundo depende de uma determinada língua ou linguagem (Ibid., p. 231). A respeito da relação entre concepção de mundo e linguagem, cf. também THURNHER, R. Sprache und Welt bei Friedrich Nietzsche. In: Nietzsche-Studien 9. Berlim e Nova York: Walter de Gruyter, 1980.

19 "Com o termo raça, [...] Nietzsche designa sempre em realidade um tipo de homem, caracterizado por um sistema pulsional particular", esclarece Patrick Wotling. Cf. NIETZSCHE, F. Par-delà bien et mal. Tradução, apresentação e notas de Patrick Wotling. Paris: Flammarion, 2000 , p. 308.
} 
É exatamente ao exame de uma função gramatical particular, a separação entre sujeito e verbo, que Nietzsche se volta para mostrar como ela vai de encontro à sua interpretação do mundo como vontade de potência e, por outro lado, conduz a uma concepção substancialista de realidade, assim como para evidenciar a que tipo de moral e de homem serve aquela distinção gramatical (GM/ GM I, 13, KSA 5.278-281) ${ }^{20}$.

Se Nietzsche considera a origem da linguagem à luz do conceito de vontade de potência, de modo a conceber toda linguagem como exteriorização de potência, deve-se precisar que, por outro lado, não é qualquer linguagem que se revela capaz de traduzir a - ou simplesmente de ir ao encontro da - interpretação do mundo como vontade de potência ${ }^{21}$. Para esclarecer esse ponto, o filósofo começa por apresentar sua tese - em consonância com sua interpretação de mundo como vontade de potência e com a moral correspondente -, segundo a qual "exigir da força que não se expresse como força, que ela $n \tilde{a} o$ seja um querer-dominar, um querer-vencer, um querer-subjugar, uma sede de inimigos, resistências e triunfos, é tão absurdo quanto exigir da fraqueza que se expresse como força. Um quantum de força equivale a um mesmo quantum de impulso, vontade, atividade" (GM/GM I, 13, KSA 5.279, trad. PCS).

Em seguida, Nietzsche explicita como aquela distinção entre sujeito e verbo segue na direção contrária da mencionada tese: "apenas sob a sedução da linguagem [...], a qual entende ou mal-entende que todo atuar é determinado por um atuante, um 'sujeito',

20 A respeito do papel da linguagem na constituição das ideias de sujeito e substância, cf. MARTON, S. Le problème du langage chez Nietzsche. La critique en tant que création, op. cit., em particular p. 232 et seq.

21 Nietzsche chama a atenção para esse aspecto quando, ao apresentar sua interpretação de mundo, sublinha "a falta de exceção e a incondicionalidade que há em toda "vontade de potência', em tal medida que quase toda palavra, e mesmo a palavra 'tirania', se mostrasse, no fim das contas, inutilizável, ou já como metáfora enfraquecedora e atenuante - por demasiado humana" (JGB/BM 22, KSA 5.37, trad. RRTF). Sobre a impossibilidade de que a concepção de mundo como vontade de potência encontre expressão numa linguagem que postula sujeito e objeto e separa um suposto agente da ação, cf., por exemplo, Nachlass/FP 1888, 14[79], KSA 13.258. 
é que [a tese de Nietzsche] pode parecer diferente" (GM/GM I, 13, KSA 5.279, trad. PCS ${ }^{22}$. Com efeito, essa linguagem advoga em benefício de uma moral popular que "discrimina entre a força e as expressões da força, como se por trás do forte houvesse um substrato indiferente que fosse livre para expressar ou não a força" (GM/ GM I, 13, KSA 5.279, trad. PCS).

Considerando que o predomínio de funções gramaticais traduz juízos de valor fisiológicos e condições de tipos (JGB/BM 20, KSA 5.35), Nietzsche procura indicar então qual perspectiva avaliadora, isto é, qual “espécie de homem necessita crer no 'sujeito' indiferente e livre para escolher" (GM/GM I, 13, KSA 5.280, trad. PCS). Nessa crença exprimem-se, segundo o filósofo, "os afetos entranhados que ardem ocultos, ódio e vingança", assim como "a vingativa astúcia da impotência" (GM/GM I, 13, KSA 5.280, trad. PCS) ${ }^{23}$. Conduzidos por um instinto de autoconservação e seduzidos por aquela distinção gramatical, os fracos postulam o sujeito como um substrato livre, separado e autor da ação, para que possam responsabilizar os fortes por exteriorizarem sua força e ao mesmo tempo possam interpretar sua própria impotência e sua própria fraqueza como algo voluntário.

$* * *$

22 Cf. Nachlass/FP 1885, 35[35], KSA 11.526: “A crença na gramática, no sujeito linguístico, no objeto, nos verbos subjugou até agora os metafísicos: eu ensino a abjurar essa crença". Mas é preciso admitir que "ainda hoje as funções gramaticais são as coisas mais bem acreditadas, diante das quais não se pode ter cautela o suficiente" (Nachlass/FP 1885, 40[27], KSA 11.643).

23 A respeito da concepção de moral como linguagem de signos dos afetos, cf. DA SILVA, I. "Zeichensprache der Affekte": le langage et la morale chez Nietzsche. In: DENAT, C.; WOTLING, P. (org.). Nietzsche. Un art nouveau du discours. Reims: Éditions et presses universitaires de Reims, 2013, p. 159-173. De fato, Nietzsche utiliza o conceito de linguagem de maneira bastante ampla, como se nota na seguinte afirmação: "As morais como linguagem de signos dos afetos: os próprios afetos, porém, uma linguagem de signos das funções de todo orgânico" (Nachlass/ FP 1883, 7[60], KSA 10.261-262). Em outra anotação próxima, o filósofo declara: "a música é uma linguagem de signos dos afetos: e mais tarde se aprenderá a reconhecer com clareza o sistema de impulsos de um músico a partir de sua música". Em seguida, acrescenta que também nos grandes filósofos o que fala é o impulso que neles se mostra mais potente. E por fim assevera: "Existem muito mais linguagens do que se pensa: e o homem se revela com uma frequência muito maior do que desejaria" (Nachlass/FP 1883, 7[62], KSA 10.262).

184 I Cad. Nietzsche, São Paulo, n. 34 - vol. I, p. 167-187, 2014. 
Num primeiro momento, Nietzsche defende que entre as coisas e, de outro lado, as palavras e os conceitos se interpõe uma série de transposições entre esferas heterogêneas, em que tem lugar, a cada vez, uma tradução para uma linguagem heterogênea. Por isso, palavras e conceitos não expressam adequadamente a realidade nem verdades absolutas, mas designam apenas relações humanas - relações que não são necessárias, nem de causalidade, tampouco de correspondência, mas estéticas. Posteriormente, Nietzsche volta-se uma vez mais ao exame dos processos de constituição das palavras e dos conceitos: agora, porém, a partir de sua própria concepção de mundo como vontade de potência. É assim que, se reporta novamente as palavras e os conceitos às sensações, o genealogista pergunta quais grupos de sensações tomam a palavra e dão as ordens. É assim que o filósofo considera os modos de instituição das palavras e dos conceitos, bem como suas significações e as associações estabelecidas entre elas, sempre como relativos a perspectivas avaliadoras, ao exercer-se de determinadas configurações de vontades de potência. Uma linguagem é, portanto, sempre relativa a uma perspectiva avaliadora, a uma certa configuração de vontades de potência.

Abstract: After formulating a relational conception of language in On
Truth and Lying in a Non-Moral Sense, Nietzsche only rarely associates
the concept of language with the concept of relation explicitly, as it occurs
in a posthumous fragment from 1888. However, we would like to propose
that at any moment the philosopher abandons his relational conception of
language; on the other hand, it seems that in the course of his work this
conception undergoes modifications, which must be identified. Keywords: language - relation - transposition - evaluating perspective 


\section{referências bibliográficas}

1. ALBRECHT, J. Friedrich Nietzsche und das "sprachliche Relativitätsprinzip". In: Nietzsche-Studien 8, p. 225-244. Berlim e Nova York: Walter de Gruyter, 1979.

2. CRAWFORD, C. The Beginnings of Nietzsche's Theory of Language. Berlim e Nova York: Walter de Gruyter, 1988.

3. DA SILVA, I. "Zeichensprache der Affekte": le langage et la morale chez Nietzsche. In: DENAT, C.; WOTLING, P. (org.). Nietzsche. Un art nouveau du discours. Reims: Éditions et presses universitaires de Reims, 2013, p. 159-173.

4. DENAT, C. "Parler par images": le statut de la rhétorique et des métaphores dans le “nouveau langage" de Nietzsche. In: DENAT, C.; WOTLING, P. (org.). Nietzsche. Un art nouveau du discours. Reims: Éditions et presses universitaires de Reims, 2013, p. 45-80.

5. GUERVÓS, L. E. de S. Introducción: El poder de la palabra: Nietzsche y la retórica. In: NIETZSCHE, F. Escritos sobre retórica. Edição, tradução e introdução de Luis Enrique de Santiago Guervós. Madrid: Editorial Trotta, 2000, p. 9-77.

6. MARTON, S. Nietzsche: das forças cósmicas aos valores humanos. Belo Horizonte: Editora UFMG, $2^{\text {a }}$ ed., 2000.

7. L_ Le problème du langage chez Nietzsche. La critique en tant que création. In: Revue de Métaphysique et de Morale, Paris, n. 2, p. 225-245, 2012.

8. MEIJERS, A. Gustav Gerber und Friedrich Nietzsche. In: Nietzsche-Studien 17, p. 369-390. Berlim e Nova York: Walter de Gruyter, 1988.

9. MEIJERS, A.; STINGELIN, M. Konkordanz zu den Wörtlichen Abschriften und Übernahmen von Beispielen und Zitaten aus Gustav Gerber: Die Sprache als Kunst (Bromberg 1871) in Nietzsches Rhetorik-Vorlesung und in 'Ueber Wahrheit und Lüge im aussermoralischen Sinne’. In: Nietzsche-Studien 17, p. 350-368. Berlim e Nova York: Walter de Gruyter, 1988.

10. MÜLLER-LAUTER, W. Nietzsches Lehre vom Willen zur Macht. In: NietzscheStudien 3, p. 1-60. Berlim e Nova York: Walter de Gruyter, 1974.

11. NIETZSCHE, F. Friedrich Nietzsche: Sämtliche Werke. Kritische Studienausgabe. Organizada por Giorgio Colli e Mazzino Montinari. München: Walter de Gruyter, 1999.

13. Kritische Gesamtausgabe Werke. Berlim e Nova York: Walter de Gruyter, v. II/2: 1993, v. II/4: 1995.

14. _ Friedrich Nietzsche: Obras incompletas. Tradução de Rubens Rodrigues Torres Filho. São Paulo: Editora Nova Cultural, 2000.

186 | Cad. Nietzsche, São Paulo, n. 34-vol. I, p. 167-187, 2014. 
15. Além do bem e do mal: prelúdio a uma filosofia do futuro. Tradução de Paulo César de Souza. São Paulo: Companhia das Letras, 2005.

16. Genealogia da moral: uma polêmica. Tradução de Paulo César de Souza. São Paulo: Companhia das Letras, 1998.

17. _. Par-delà bien et mal: prélude à une philosophie de l'avenir. Tradução, apresentação e notas de Patrick Wotling. Paris: Flammarion, 2000.

18. THURNHER, R. Sprache und Welt bei Friedrich Nietzsche. In: Nietzsche-Studien 9 , p. 38-60. Berlim e Nova York: Walter de Gruyter, 1980.

19. WOTLING, P. What Language Do Drives Speak? In: CONSTÂNCIO, J.; BRANCO, M. J. M. (Ed.). Nietzsche on Instinct and Language. Berlim e Boston: de Gruyter, 2011, p. 63-79.

20. ZAVATTA, B. Die in der Sprache versteckte Mythologie und ihre Folgen fürs Denken. Einige Quellen von Nietzsche: Max Müller, Gustav Gerber und Ludwig Noiré. In: Nietzsche-Studien 38, p. 269-298. Berlim e Nova York: Walter de Gruyter, 2009.

Artigo recebido para publicação em 18/06/2103.

Artigo aceito para publicação em 30/07/2013. 